\title{
Efficient Conversion of Oximes to the Corresponding Carbonyl Compounds with Tetrabutylammonium Chromate under Aprotic Conditions
}

\author{
Ali Reza Pourali* and Arezou Goli \\ School of Chemistry, Damghan University of Basic Sciences, Damghan 36715/364, Iran. *E-mail: pourali@dubs.ac.ir \\ Received October 28, 2005
}

Key Words : Oximes, Carbonyl, Deprotection, Quaternary ammonium salt

Oximes are extensively used as preferred and readily prepared derivatives for purification and characterization of carbonyl compounds. ${ }^{1}$ Furthermore they play an important role as protecting ${ }^{2}$ and selectively a-activating ${ }^{3}$ groups in synthetic organic chemistry. Regeneration of ketones and aldehydes from their oximes has assumed added importance since the discovery of the Barton reaction in which oximes are produced at non-activated hydrocarbon sites. ${ }^{4}$ Also, their synthesis from non-carbonyl compounds, such as by nitrosation of an active methylene group, ${ }^{5}$ nitrosation of an $\alpha$-halo carbonyl compound ${ }^{6}$ and condensation of a nitroalkene with an aldehyde ${ }^{7}$ provides a valid alternative pathway to carbonyl compounds. Therefore, there has been a continued interest in the effective regeneration of carbonyl compounds from the corresponding oximes especially under mild conditions. ${ }^{8-10}$ Oxidative and reductive methods have been found to show advantages over the classical hydrolytic methods. ${ }^{8}$ Although many oxidizing agents have been used, only a limited number of methods are efficient because of the low solubility of these metallic reagents in most organic solvents. ${ }^{11,12}$

A number of oxidative deoximation methods have been developed which involve chromium (VI) species, ${ }^{13-19}$ but most of them suffers from low yields or long reaction times. Some quaternary ammonium salts such as triethylammonium chlorochromate, ${ }^{20}$ prolinium chlorochromate/silica $\mathrm{gel}^{21}$ and bis(tetrabutylammonium) dichromate under microwave irradiation $^{22}$ have shown good yields in deoximation reactions. However, cleavage of aldoximes into carbonyl compounds requires milder reagents to avoid further oxidation. For example, benzaldehyde was obtained from the reaction of corresponding oxime with triethylammonium chlorochromate in only $56 \%$ yield. ${ }^{20}$ Many easily prepared or commercially available crystalline quaternary ammonium salts of different oxidizing anions have been studied and found some applications in functional group interconversions. ${ }^{19-25}$ For some reasons, it is attractive to use quaternary
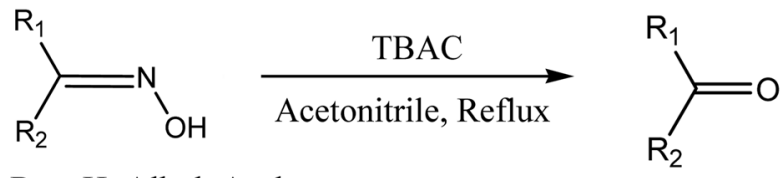

$\mathrm{R}_{1}, \mathrm{R}_{2}=\mathrm{H}$, Alkyl, Aryl ammonium salts as reagents for organic transformations. The solubility of these salts in several solvents, selectivity, and absence of side reactions provides advantages of using them in organic synthesis. Tetrabutylammonium chromate (TBAC) is one of these compounds that has been used as a very mild oxidizing agent for conversion of unsaturated alcohols including allylic and benzylic alcohols to the corresponding aldehydes with the double bonds intact. ${ }^{25}$

In continuation of our ongoing research program on the use of quaternary ammonium salts as reagents for the approach to novel synthetic methods, ${ }^{26-27}$ we now report efficient conversion of oximes into the corresponding carbonyl compounds by using tetrabutylammonium chromate under homogeneous, aprotic and moderately acidic conditions. We found that the oxidative deprotection of oximes can be easily performed with tetrabutylammonium chromate by refluxing the reaction mixture in acetonitrile

Table 1. Conversion of oximes to the corresponding carbonyls by $\mathrm{TBAC}^{a}$

\begin{tabular}{ccccc}
\hline Entry & $\mathrm{R}_{1}$ & $\mathrm{R}_{2}$ & Time (Min.) & ${\text { Yield } \%^{b}}^{b}$ \\
\hline 1 & $\mathrm{C}_{6} \mathrm{H}_{5}$ & $\mathrm{H}$ & 5 & 95 \\
2 & $4-\mathrm{ClC}_{6} \mathrm{H}_{4}$ & $\mathrm{H}$ & 20 & 95 \\
3 & $2-\mathrm{OH}_{-} \mathrm{C}_{6} \mathrm{H}_{4}$ & $\mathrm{H}$ & 20 & 87 \\
4 & & & & 86 \\
& & & & \\
\end{tabular}

${ }^{a}$ All reactions were performed in $\mathrm{CH}_{3} \mathrm{CN}$ at reflux conditions. ${ }^{b}$ Yield of isolated product; all the products have been described in literature and were identified by their melting points and IR or H-NMR spectra. 
(Scheme 1).

The results show that the corresponding carbonyl compounds can be obtained in good to excellent yields (Table 1). According to the results, this method is suitable for the deprotection of oximes under mild conditions in $\mathrm{CH}_{3} \mathrm{CN}$ as an aprotic solvent. For example, benzaldehyde was obtained from benzaldehyde oxime after 5 minutes in $95 \%$ yield (Table 1, Entry 1). No over-oxidation of benzaldehyde to benzoic acid was observed in these conditions. Other aldehydes were also obtained selectively via deoximation of the corresponding oximes without any over-oxidation (Table 1, Entries 2-5).

In conclusion, the solubility in several solvents, mildness, simple work-up and absence of side reactions provide advantages of using TBAC in deoximation reactions. This is an efficient and selective method for homogeneous deoximation of structurally different compounds under the moderately acidic and aprotic conditions in high yields.

\section{Experimental Section}

General. Chemicals were obtained from Merck and Fluka chemical companies. All compounds were known and are identified by comparison of their physical and spectroscopic data with those of authentic samples. Melting points were determined in open capillary tubes with a Buchi 510 apparatus. FT-IR spectra were recorded on a Perkin Elmer RXI spectrometer. NMR spectra were recorded on a Brucker Avance DPX $250 \mathrm{MHz}$ instrument. The products were purified by column chromatography and the purity determination of the products was accomplished by GLC on a Shimadzu model GC 10-A instrument or by thin layer chromatography on silica gel polygram on SIL G/UV 254 plates.

Preparation of TBAC. ${ }^{25}$ A solution of tetrabutylammonium hydrogen sulfate $(3.56 \mathrm{~g}, 10.5 \mathrm{mmol})$ in water $(50 \mathrm{~mL})$ was added to an aqueous solution $(25 \mathrm{~mL})$ of chromium trioxide $(1.0 \mathrm{~g}, 10 \mathrm{mmol})$ at room temperature. The immediately formed yellow-orange precipitate was filtered, washed with cold water and dried under vacuum and stored over calcium chloride; yield: $2.87 \mathrm{~g}(80 \%)$.

Typical Procedure. Deprotection of acetophenone oxime with TBAC: To a solution of acetophenone oxime $(0.135 \mathrm{~g}$, $1 \mathrm{mmol})$ in $\mathrm{CH}_{3} \mathrm{CN}(5 \mathrm{~mL})$, was added tetrabutylammonium chromate $(0.360 \mathrm{~g}, 1 \mathrm{mmol})$. The reaction mixture was refluxed. The progress of the reaction was monitored by TLC or GC. After 40 min., the reaction mixture was work- ed-up by adding distilled water $(5 \mathrm{~mL})$ and then filtering. Extraction of mixture by dichloromethane $(2 \times 20 \mathrm{~mL})$ and column chromatography using petroleum ether-EtOAc $(5$ : 1) as eluent gave acetophenone; Yield $0.108 \mathrm{~g}(90 \%)$ as colorless liquid; b.p. $200-204{ }^{\circ} \mathrm{C} / 760 \mathrm{~mm} \mathrm{Hg}$ [Lit. ${ }^{24} 204{ }^{\circ} \mathrm{C} /$ $760 \mathrm{~mm} \mathrm{Hg}$.

Acknowledgement. Partial support of this work by DUBS Research Council is gratefully acknowledged.

\section{References}

1. Cheronis, N. D.; Entrikin, J. B. Identification of Organic Compounds; Wiley, Interscience: New York, 1963.

2. Greene, J. G.; Wuts, P. G. M. Protective Groups in Organic Synthesis, 2nd Ed.; John Wiley: New York, 1991.

3. Whitesell, J. K.; Whitesell, M. A. Synthesis 1983, 54.

4. Barton, D. H. R.; Beaton, J. M.; Geller, L. E.; Pechell, M. M. J. Am. Chem. Soc. 1961, 83, 4083.

5. Barry, R. H.; Hartune, W. M. J. Org. Chem. 1957, 12, 460.

6. Hartung, W. M.; Crossley, F. Org. Synth. Coll. Vol. II 1943, 263.

7. Hasi, H. B.; Susie, A. G.; Heider, R. L. J. Org. Chem. 1950, 15, 8.

8. Corsaro, A.; Chiacchio, U.; Pistara, V. Synthesis 2001, 1903.

9. Ranu, B. C.; Sarkar, D. C. J. Org. Chem. 1988, 53, 878.

10. Shirini, F.; Zolfigol, M. A.; Mallakpour, B.; Mallakpour, S. E.; Hajipour, A. R.; Baltork, I. M. Tetrahedron Lett. 2002, 43, 1555.

11. Maloney, J. R.; Lyle, R. E.; Saavedra, J. E.; Lyle, G. L. Synthesis 1978, 212.

12. Salmon, M.; Miranda, R.; Angeles, E. Synth. Commun. 1986, 16, 1827.

13. Narayanan, N.; Balasubramanian, T. R. J. Chem. Res. (S) 1992, 4, 132.

14. Maloney, J. R.; Lyle, R. E.; Scovedra, J. E.; Lyle, G. G. Synthesis 1978, 212.

15. Drabowicz, J. Synthesis 1980, 125.

16. Lee, J. G.; Kwak, K. H.; Hwang, J. P. Synth. Commun. 1992, 22, 2425.

17. Aizpurua, J. M.; Juaristi, M.; Lecea, B.; Palomo, C. Tetrahedron 1985, 41, 2903.

18. Hamal, S.; Mahto, S. K.; Gujurel, G. L. Indian J. Chem. B 1996, 35(B), 1116

19. Zhang, G. S.; Yang, D. H.; Chen, M. F.; Cai, K. Synth. Commun. 1998, 28, 607.

20. Rao, C. G.; Radhakrishna, A. S.; Singh, B. B.; Bhatnagar, S. P. Synthesis 1983, 808.

21. Shirini, F.; Mamaghani, M.; Parsa, F.; Baltork, I. M. Bull. Korean Chem. Soc. 2002, 23, 1683.

22. Murugan, R.; Reddy, B. S. R. Chem. Lett. 2004, 33, 1038.

23. Hajipour, A. R.; Mahboubghah, N. J. Chem. Res. (S) 1998, 122.

24. Hajipour, A. R.; Baltork, I. M.; Kianfar, G. Bull. Chem. Soc. Jpn. 1998, 71, 2655

25. Cacchi, S.; Torre, F.; Misiti, D. Synthesis 1979, 356.

26. Akhlaghinia, B.; Pourali, A. R. Synthesis 2004, 1747.

27. Pourali, A. R. Monatsh. Chem. 2005, 136, 733. 